\title{
Antimicrobial susceptibility patterns of community-acquired uropathogens in Tehran, Iran
}

\author{
Nasim Kashef ${ }^{1}$, Gholamreza Esmaeeli Djavid ${ }^{2}$, Sahba Shahbazi ${ }^{1}$ \\ ${ }^{1}$ Department of Microbiology, School of Biology, College of Sciences, University of Tehran, Tehran, Iran \\ ${ }^{2}$ Academic Center for Education, Culture and Research, Tehran, Iran
}

\begin{abstract}
Background: Antibiotic resistance of urinary tract pathogens has increased worldwide. Knowledge of the antibiotic resistance patterns of uropathogens in specific geographical locations is an important factor for choosing an appropriate empirical antimicrobial treatment. The aim of this study was to provide information regarding local resistance patterns of urinary pathogens to the commonly used antibiotics in Tehran, Iran.

Methodology: Urine samples collected and submitted to two pathobiology laboratories in Tehran were identified by conventional methods over a period of three years (December 2006 to May 2009). Antimicrobial resistance testing was performed by the standard disk diffusion technique in accordance with the recommendations of the Clinical and Laboratory Standards Institute.

Results: Of the total 13,333 mid-stream urine samples collected from suspected cases of urinary tract infection, 840 (6.3\%) were positive for pathogenic bacteria. Escherichia coli (E. coli) was the most common isolate (68.8\%) followed by Proteus spp. (12.4\%), and Klebsiella spp. (9.6\%). E. coli isolates were mostly susceptible to nitrofurantoin (71.3\%), followed by ciprofloxacin (68.1\%); however, only $38.2 \%$ of $E$. coli isolates were susceptible to trimethoprim-sulfamethoxazole.

Conclusion: Nitrofurantoin may be considered as a first-line empiric antibacterial agent for urinary tract infections in outpatients in Tehran, Iran.
\end{abstract}

Key words: urinary tract infection, antimicrobial susceptibility, uropathogens

J Infect Dev Ctries 2010; 2010; 4(4):202-206.

(Received 28 September 2009 - Accepted 19 January 2010)

Copyright (C) 2010 Kashef et al. This is an open-access article distributed under the Creative Commons Attribution License, which permits unrestricted use, distribution, and reproduction in any medium, provided the original work is properly cited.

\section{Introduction}

Urinary tract infection (UTI) is not only a common outpatient affliction, but also the most frequently occurring nosocomial infection [1,2]. UTI can be classified into uncomplicated and complicated infections with respect to choices for treatment [1]. Among both outpatients and inpatients, Escherichia coli (E. coli) is the most common etiological agent, accounting for $75 \%$ to $90 \%$ of uncomplicated UTI isolates [3,4], while complicated UTI exhibit a broader bacterial spectrum as the cause of infection [1].

The incidence of UTI is greater in women as compared to men, which may be either due to anatomical predisposition or urothelial mucosa adherence to the mucopolysaccharide lining or other host factors [5]. Sexual activity, pregnancy, and obstruction also increase the frequency of UTI [6].

In almost all cases of UTI, empirical antimicrobial treatment initiates before the laboratory results of urine culture are available; thus antibiotic resistance may increase in uropathogens due to frequent misuse of antibiotics [7,8]. For this reason, knowledge of the etiological agents of UTIs and their antimicrobial resistance patterns in specific geographical locations may aid clinicians in choosing the appropriate antimicrobial empirical treatment. Our study was conducted to determine the antimicrobial susceptibility patterns of commonly used antibiotics among community-acquired uropathogens during a three-year period from 2006 to 2009.

\section{Materials and methods}

This study was approved by the Institutional Review Board of the University of Tehran.

The study was conducted in two general laboratories that serve outpatients in the western and central parts of Tehran. The study population consisted of all patients having positive communityacquired urine cultures with a colony count of $\geq 10^{5}$ $\mathrm{CFU} / \mathrm{mL}$. Community acquired isolates were defined 
as a culture collection from a patient not admitted to the hospital. The study was retrospective with an observation period of three years (December 2006 to May 2009). Data on age, sex, result of urine culture, etiological agent, and susceptibility pattern were obtained from the medical records of patients.

A total of 13,333 midstream urine samples were collected in sterile containers from suspected cases of urinary tract infections in two general laboratories (Danesh and Ferdous Pathobiology Laboratories). Each adult patient was carefully instructed regarding the collection of a mid-stream urine sample. Urine samples were obtained by sterile urine bags in infants after disinfecting the perineum.

Urine culture was done using a calibrated loop. Samples were inoculated on blood agar and eosin methylene blue agar plates then were read after overnight incubation at $37^{\circ} \mathrm{C}$. For this study, significant bacteriuria was defined as culture of a single bacterial species from the urine sample at a concentration of $10^{5} \mathrm{CFU} / \mathrm{mL}$ associated with microscope findings of $>10 \mathrm{WBC}$ per high power field [9]. Such urine samples were further processed for identification and antibacterial susceptibility of the uropathogen. When the count was less than $10^{5}$ $\mathrm{CFU} / \mathrm{ml}$, it was considered as non-significant bacteriuria or negative.

Identification of bacterial pathogens was made on the basis of Gram reaction, morphology, and biochemical features. All culture media were purchased from Merck, Germany.

Isolates were tested for antimicrobial susceptibility by the standard disk diffusion method according to Bauer et al. [10]. Mueller-Hinton agar plates were incubated for 24 hours after inoculation with organisms and placement of the disks and inhibition zones were measured. Antibiotic disks were obtained from Padtanteb Company, Iran. The commercial antibiotics used for isolates included ciprofloxacin (CP), trimethoprim-sulfamethoxazole (SXT), gentamicin (GM), ampicillin (AM), nitrofurantoin (FM), nalidixic acid (NA), Ceftriaxone (CRO), ceftizoxime (CT), cephalexin (CN), cephalothin (CF), amoxicillin (AMX), carbenicillin (CB), norfloxacin (NOR), ceftazidime (CAZ), penicillin $(\mathrm{P})$, erythromycin $(\mathrm{E})$, and vancomycin $(\mathrm{V})$; P, E, and V were used for gram positive bacteria. The results were interpreted according to CLSI (formerly NCCLS) 2000 [11].

Statistical analysis was performed using SPSS, version 13 (SPSS Inc., Chicago, IL, USA).

\section{Results}

A total of 13,333 urine samples were analyzed for isolation and identification of bacterial isolates. Of these, $840(6.3 \%)$ samples were found to be significant bacteriuria and the remaining 12,493 samples were either non-significant bacteriuria or had a very low bacterial count or were sterile urine.

Among the all patients, $85.2 \%$ were female. Ages ranged from one to 94 years with an average age of $48.5(\mathrm{SD}=21.8)$ years. The mean age of male and female patients was $53.5(\mathrm{SD}=20.8)$ years and 47.6 $(\mathrm{SD}=21.8)$ years, respectively.

Table 1 illustrates the overall frequency and rank order of community-acquired uropathogens. As expected, E. coli was the most frequently reported isolate $(68.8 \%)$.

Gram-positive organisms included only $5.3 \%$ of the isolates in our study.

Antimicrobial susceptibility results are summarized in Table 2. E. coli isolates were mostly susceptible to nitrofurantoin (71.3\%), followed by ciprofloxacin $(68.1 \%)$. E. coli isolates had the highest resistance rate to ampicillin and amoxicillin (85.9\% and $95.2 \%$, respectively). Importantly, only $38.2 \%$ of $E$. coli isolates were susceptible to trimethoprimsulfamethoxazole. Proteus spp. showed the highest sensitivity to ciprofloxacin $(71.2 \%)$ and the highest resistance to ampicillin (88.3\%) and to cephalothin $(58.3 \%)$. Klebsiella spp. had the highest sensitivity to ciprofloxacin (81.3\%) and showed the highest resistance rate to ampicillin and amoxicillin $(94.5 \%$ and $88.5 \%$, respectively).

Pseudomonas, which has a high resistance rate worldwide, was $100 \%$ resistant to ampicillin, $92.9 \%$ to nalidixic acid and $88.9 \%$ to nitrofurantoin. The best activity against Pseudomonas (75\% susceptible) was attained with ciprofloxacin.

Table 1. Frequency of community-acquired uropathogens.

\begin{tabular}{|l|c|}
\hline \multicolumn{1}{|c|}{ Organism } & No. of isolates (\%) \\
\hline E. coli & $578(68.8)$ \\
\hline Proteus spp. & $104(12.4)$ \\
\hline Klebsiella spp. & $81(9.6)$ \\
\hline Pseudomonas spp. & $28(3.3)$ \\
\hline Streptococcus spp. & $19(2.3)$ \\
\hline Enterococcus spp. & $11(1.3)$ \\
\hline Coagulase-Negative Staphylococci ${ }^{2}$ & $9(1.1)$ \\
\hline Staphylococcus aureus & $5(0.6)$ \\
\hline Enterobacter spp. & $3(0.4)$ \\
\hline Citrobacter spp. & $2(0.2)$ \\
\hline
\end{tabular}

'includes non-hemolytic streptococci (1), $\alpha$-hemolytic streptococci (2), and $\beta$-hemolytic streptococci (16) ${ }^{2}$ includes S. saprophyticus (4) and S. epidermidis (5) 
Table 2. Antimicrobial susceptibility among community-acquired uropathogens. Note that intermediate categories are not mentioned.

\begin{tabular}{|c|c|c|c|c|c|c|c|c|c|c|c|c|c|c|c|c|c|c|c|c|}
\hline \multirow{5}{*}{$\begin{array}{l}\text { Ciprofloxacin } \\
\text { Norfloxacin } \\
\text { Nalidixic acid }\end{array}$} & \multicolumn{2}{|c|}{$\begin{array}{l}\text { E. coli } \\
(578)\end{array}$} & \multicolumn{2}{|c|}{$\begin{array}{l}\text { Proteus } \\
\text { spp. } \\
(104)\end{array}$} & \multicolumn{2}{|c|}{$\begin{array}{c}\text { Klebsiella } \\
\text { spp. (81) }\end{array}$} & \multicolumn{2}{|c|}{$\begin{array}{l}\text { Pseudomonas } \\
\text { spp. } \\
\text { (28) }\end{array}$} & \multicolumn{2}{|c|}{$\begin{array}{l}\text { Streptococccus } \\
\text { spp. (19) }\end{array}$} & \multicolumn{2}{|c|}{$\begin{array}{c}\text { Enterococcus } \\
\text { spp. } \\
\text { (11) }\end{array}$} & \multicolumn{2}{|c|}{$\begin{array}{l}\text { CoNS } \\
(9)\end{array}$} & \multicolumn{2}{|c|}{$\begin{array}{l}\text { S. aureus } \\
\text { (5) }\end{array}$} & \multicolumn{2}{|c|}{$\begin{array}{c}\text { Enterobacter } \\
\text { spp. } \\
\text { (3) }\end{array}$} & \multicolumn{2}{|c|}{$\begin{array}{c}\text { Citrobacter } \\
\text { spp. } \\
(2)\end{array}$} \\
\hline & $\# \mathrm{~T}^{1}$ & $\% \mathrm{~S}^{2}$ & \#T & $\% \mathrm{~S}$ & \#T & $\% \mathrm{~S}$ & $\# \mathrm{~T}$ & $\% \mathrm{~S}$ & $\# \mathrm{~T}$ & $\% \mathrm{~S}$ & \#T & $\% \mathrm{~S}$ & \#T & $\% \mathrm{~S}$ & \#T & $\% \mathrm{~S}$ & $\# \mathrm{~T}$ & $\% \mathrm{~S}$ & \#T & $\% \mathrm{~S}$ \\
\hline & 564 & 68.1 & 104 & 71.2 & 80 & 81.3 & 28 & 75 & - & - & - & - & - & - & - & - & 3 & 100 & 2 & 100 \\
\hline & 234 & 62 & - & - & 24 & 91.7 & 5 & 80 & 15 & 86.7 & 10 & 60 & 9 & 88.9 & 4 & 75 & 2 & 100 & 1 & 100 \\
\hline & 577 & 30.5 & 104 & 10.6 & 81 & 43.2 & 28 & 3.6 & 15 & 6.7 & 10 & 10 & 9 & 0 & 4 & 0 & 3 & 66.7 & 2 & 100 \\
\hline Gentamicin & 578 & 49.3 & 104 & 7.7 & 81 & 53.1 & 28 & 21.4 & 15 & 0 & 11 & 18.2 & 9 & 88.9 & 4 & 100 & 3 & 33.3 & 2 & 100 \\
\hline Nitrofurantoin & 575 & 71.3 & 104 & 42.3 & 81 & 27.2 & 27 & 3.7 & 14 & 100 & 11 & 90.9 & 9 & 88.9 & 4 & 75 & 3 & 33.3 & 2 & 100 \\
\hline Penicillin & - & - & - & - & - & - & - & - & 13 & 7.7 & 11 & 0 & 8 & 12.5 & 4 & 0 & - & - & - & - \\
\hline Ampicillin & 304 & 3.6 & 103 & 1 & 55 & 0 & 22 & 0 & - & - & - & - & - & - & - & - & - & - & - & - \\
\hline Amoxicillin & 271 & 2.6 & - & - & 26 & 11.5 & 6 & 0 & 15 & 93.3 & 11 & 45.5 & 8 & 25 & 4 & 75 & 3 & 33.3 & 2 & 50 \\
\hline Carbenicillin & 269 & 72.9 & - & - & 26 & 96.2 & 6 & 50 & - & - & - & - & - & - & - & - & 3 & 100 & 2 & 100 \\
\hline Cephalexin & 304 & 11.5 & 103 & 2.9 & 55 & 9.1 & 22 & 4.5 & - & - & - & - & - & - & - & - & - & - & - & - \\
\hline Cephalothin & 304 & 15.1 & 103 & 1.9 & 55 & 12.7 & 22 & 4.5 & - & - & - & - & - & - & - & - & - & - & - & - \\
\hline Ceftazidime & 247 & 62.8 & - & - & 23 & 82.6 & 6 & 83.3 & - & - & - & - & - & - & - & - & 2 & 100 & 2 & 100 \\
\hline Ceftriaxone & 304 & 63.5 & 103 & 40.8 & 55 & 47.3 & 22 & 9.1 & - & - & - & - & - & - & - & - & - & - & - & - \\
\hline Ceftizoxime & 304 & 64.1 & 103 & 39.8 & 55 & 61 & 22 & 13.6 & - & - & - & - & - & - & - & - & - & - & - & - \\
\hline $\begin{array}{l}\text { Trimethoprim- } \\
\text { sulfamethoxazole }\end{array}$ & 578 & 38.2 & 104 & 22.1 & 81 & 46.9 & 28 & 10.7 & 15 & 0 & 11 & 18.2 & 9 & 88.9 & 4 & 75 & 3 & 100 & 2 & 100 \\
\hline Erythromycin & - & - & - & - & - & - & - & - & 14 & 64.3 & 10 & 10 & 9 & 77.8 & 3 & 66.7 & - & - & - & - \\
\hline Vancomycin & - & - & - & - & - & - & - & - & 14 & 85.7 & 11 & 18.2 & 9 & 66.7 & 4 & 100 & - & - & - & - \\
\hline
\end{tabular}




\section{Discussion}

The worldwide trend of empirically treating community acquired UTI may not apply to specific geographical regions such as Iran, where decreased susceptibility rates are documented for common urinary pathogens [12,23-25]. Therefore, it is important to monitor the status of antimicrobial resistance among uropathogens to improve treatment recommendations. We conducted this study to determine the frequency and antimicrobial susceptibility patterns of community-acquired uropathogens in our region.

Our study was retrospective using the results of routine diagnostic and susceptibility analysis in two general laboratories of Tehran, Iran. Our data was restricted to patients who can afford medical analysis; therefore, this study may not reflect the true prevalence of UTI among patients in Tehran as most patients are initially treated empirically for their UTI. Also, susceptibility testing was not complete for all antimicrobials used to treat UTIs caused by uropathogens.

In our study, as in several previous reports, the most commonly isolated organism in UTI was $E$. coli, involving $68.8 \%$ of the positive samples [1214]. The proportion of bacterial species isolated was similar to those described in several previous studies $[12,13,15,16]$. Proteus spp. was the second most common organism followed by Klebsiella spp. and Pseudomonas spp.

The frequency of UTI is greater in women as compared to men [5,13], and our results were similar to these reports; $85.2 \%$ of all patients were female.

Trimethoprim-sulfamethoxazole,

fluoroquinolone, or nitrofurantoin are recommended for empirical treatment of uncomplicated UTI $[17,18]$. However, studies from the United States of America and worldwide indicate the emergence of high levels of trimethoprim-sulfamethoxazole resistance in a significant percentage $(>20 \%)$ of community-acquired E. coli UTI isolates [19-22]. We also found a high level of resistance to this antimicrobial agent [54\%]. Other Iranian studies reported similar results $[23,24]$. These findings indicate that initial empirical treatment with trimethoprim-sulfamethoxazole is no longer appropriate in Tehran.

The fluoroquinolones tested in this study (ciprofloxacin and norfloxacin) show relatively good activity against $E$. coli, finding that $68.1 \%$ and $62 \%$ of the E. coli strains were susceptible to ciprofloxacin and norfloxacin, respectively. This result, which was lower than that obtained by another Iranian study [25], may be due to a shift in antibiotic prescription toward fluoroquinolones in recent years in Iran. These findings indicate that the empiric use of fluoroquinolones should be seriously reconsidered in our region, or that strategies to counteract increased resistance to these antibiotics must be developed.

Nitrofurantoin demonstrated better activity against E. coli isolates ( $71.3 \%$ susceptible), but this drug would not be recommended for serious upper urinary tract infections or for those cases with systemic involvement [26].

According to a Turkish study [27], E. coli isolates were highly resistant to ampicillin (47.8\% to $64.6 \%$ ) and higher resistance rates to ampicillin have been reported in other countries including Senegal $(77 \%)$, Spain $(65 \%)$, Taiwan $(80 \%)$, and India $(88 \%)$ [28-31]. In our study, the ampicillin resistance rate was $88 \%$. The beta $(\beta)$-lactam antibiotics such as ampicillin have other problems besides resistance. They are found to have relatively poor action in treating symptomatic cystitis. One hypothesis is that it is rapidly excreted and the duration of significant drug concentration in the urine is short. The other reason is that $\beta$-lactams are relatively ineffective in clearing Gram-negative rods from the vaginal and colonic mucosa, thus possibly predisposing to recurrences when used to treat UTI $(18,32)$.

In conclusion, trimethoprim-sulfamethoxazole is not recommended as a first choice for treatment of UTI in Tehran area. Nitrofurantoin may be considered as a first-line empiric agent in outpatients. As resistance to fluoroquinolones is increasing in the community for E. coli, severely curtailing fluoroquinolone use in uncomplicated infections is recommended.

\section{Acknowledgement}

Support was provided by the School of Biology, College of Sciences, University of Tehran. We would like to thank staff members of Danesh and Ferdous Pathobiology Laboratories for their skillful technical support.

\section{References}

1. Wagenlehner FM, Naber KG, Weidner W (2008) Rational antibiotic therapy of urinary tract infections. Med Monatsschr Pharm31: 385-90.

2. Siddiqui AA (2008) Prevalence of quinolone-resistant urinary tract infections in Comanche County Memorial Hospital. J Okla State Med Assoc 101: 210-12.

3. Gupta K, Hooten TM, Stamm WE (2001) Increasing antimicrobial resistance and the management of uncomplicated community-acquired urinary tract infections. Ann Intern Med 135: 41-50. 
4. Nicolle LE (2001) Epidemiology of urinary tract infection. Infect Med 18:153-62.

5. Schaeffer AJ, Rajan N Cao Q, Anderson BE, et al. (2001) Host pathogenesis in urinary tract infection. Int $\mathbf{J}$ Antimicrob Agents 17: 245-51.

6. Stamm WE (2005) Urinary tract infections and pyeloephritis. In: Kasper DL, Braunwald E, Fausi AS, et al. (editors) Harrison's Principles of Internal Medicine. 16th ed. McGraw-Hill companies, Inc., USA, 1715-721.

7. Tambekar DH and Dhanorkar DV (2005) The prevalence and antibiogram of potential bacterial pathogens in clinical specimens. 46th Annual Conference of Association of Microbiologist of India, Department of Microbiology, Osmania University, Hyderabad, Dec. 8-10.

8. Tambekar DH and Khandelwal VK (2005) Antibiogram of urinary tract pathogens. 46th annual conference of association of Microbiologist of India, Osmania University, Hydrabad, Dec. 8-10.

9. Kass EH (1957) Bacteriuria and the diagnosis of infection in the urinary tract. Arch Intern Med 100: 709-14.

10. Bauer AW, Kirby WM, Sherries JC, Truck M (1996) Antibiotic susceptibility testing by a standardized single disk method. Am J Clinical Pathol 6: 493-96.

11. National Committee for Clinical Laboratory Standards (2000) Performance standards for antimicrobial disc susceptibility tests. 7th ed. Wayne, Pennsylvania, USA: NCCLS, M2-A7.

12. Sharifian M, Karimi A, Rafiee-Tabatabaei S, et al. (2006) Microbial sensitivity pattern in urinary tract infections in children: a single center experience of 1177 urine cultures. Jpn J Infec Dis 59: 380-82.

13. Keah S, Wee E, Chng K, et al. (2007) Antimicrobial susceptibility of community-acquired uropathogens in general practice. Malaysian Family Physician 2: 64-69.

14. Kothari A and Sagar V (2008) Antibiotic resistance in pathogens causing community-acquired urinary tract infections in India: a multicenter study. J Infect Developing Countries 2: 354-58.

15. Zhanel GG (2005) Antibiotic resistance in outpatient urinary isolates: final results from the North American Urinary Tract Infection Collaborative Alliance (NAUTICA). Int $\mathbf{J}$ Antimicrob Agents 26: 380-88.

16. Andrade SS, Sader HS, Jones RN, et al. (2006) Increased resistance to first-line agents among bacterial pathogens isolated from urinary tract infections in Latin America: time for local guidelines? Mem Inst Oswaldo Cruz 101: 741-48.

17. Echols RM and Tosiello RL, Haverstock DC, et al. (1999) Demographic, clinical, and treatment parameters influencing the outcome of acute cystitis. Clin Infect Dis 29: 113-19.

18. Warren JW, Abrutyn E, Hebel JR, et al. (1999) Guidelines for antimicrobial treatment of uncomplicated acute bacterial cystitis and acute pyelonephritis in women. Clin Infect Dis 29: 745-758

19. Karlowsky JA, Jones ME, Thornsberry C (2001) Prevalence of antimicrobial resistance among urinary tract pathogens isolated from female outpatients across the USA in 1999. Int J Antimicrob Agents 18: 121-7.

20. Dias Neto J, Martins ACP, da Silva LDM, Tiraboschi RB, Domingos ALA, Cologna AJ, Paschoalin ED, Tucci Jr S (2003) Community-acquired urinary tract infections: etiology and bacterial susceptibility. Acta Cir Bras 18: suppl. 5.

21. Al-Tawfiq JA (2006) Increasing antibiotic resistance among isolates of Escherichia coli recovered from inpatients and outpatients in a Saudi Arabian hospital. Infect Control Hosp Epidemiol 27: 748-53.

22. Akram M, Shahid M, Khan AU (2007) Etiology and antibiotic resistance patterns of community-acquired urinary tract infections in JNMC Hospital Aligarh, India. Ann Clin Microbiol Antimicrob 6: 4.

23. Haghi-Ashteiani M, Sadeghifard N, Abedini M, et al. (2007) Etiology and antibacterial resistance of bacterial urinary tract infections in Children's Medical Center, Tehran, Iran. Acta Medica Iranica 45: 153-57.

24. Rashedmarandi F, Rahnamayefarzami M, Saremi M, et al. (2008) A survey on urinary pathogens and their antimicrobial susceptibility among patients with significant bacteriuria. Iranian Journal of Pathology 3: 191-96.

25. Jazayeri Moghadas A and Irajian G (2009) Asymptomatic urinary tract infection in pregnant women. Iranian Journal of Pathology 4: 105-08.

26. Vasquez Y, and Hand WD (2004) Antibiotic susceptibility patterns of community-acquired urinary tract isolates from female patients on the US (Texas) - Mexico border. The Journal of Applied Research 4: 321-26.

27. Kurutepe S, Surucuoglu S, Sezgin C, et al. (2005) Increasing antimicrobial resistance in Escherichia coli isolates from community-acquired urinary tract infections during 19982003 in Manisa, Turkey. Jpn J Infect Dis 58: 159-61.

28. Dromigny JA, Nabeth P, Perrier Gros Claude JD (2002) Distribution and susceptibility of bacterial urinary tract infections in Dakar, Senegal. Int J Antimicrob Agents 20: 339-47.

29. Daza R, Gutierrez J, Piedrola G (2001) Antibiotic susceptibility of bacterial strains isolated from patients with community-acquired urinary tract infections. Int $\mathrm{J}$ Antimicrob Agents 18: 211-15.

30. Lau SM, Peng MY, Chang FY (2004) Resistance rates to commonly used antimicrobials among pathogens of both bacteremic and non-bacteremic community-acquired urinary tract infection. J Microbiol Immunol Infect 37: 185-91.

31. Gupta N, Kundra S, Sharma A, et al. (2007) Antimicrobial susceptibility of uropathogens in India. J Infect Dis Antimicrob Agents 24: 13-18.

32. Daikos GL, Kathpalia SB, Sharifi R, et al. (1987) Comparison of ciprofloxacin and beta-lactam antibiotics in the treatment of urinary tract infections and alteration of fecal flora. Am J Med 82: 290-294.

\section{Corresponding author}

Nasim Kashef

Department of Microbiology

School of Biology, College of Sciences

University of Tehran

Tehran, Iran

Phone: +98-21-61113558

Fax: +98-21-66492992

E-mail: kashefn@khayam.ut.ac.ir

Conflict of interests: No conflict of interests is declared. 